\title{
MULTISCALE TEST OF CAPM FOR THREE CENTRAL AND EASTERN EUROPEAN STOCK MARKETS
}

\author{
Silvo Dajčman¹, Mejra Festić², Alenka Kavkler ${ }^{3}$ \\ ${ }^{1}$ School of Economics and Business, Finance, University of Maribor, \\ Razlagova 14, Maribor, Slovenia \\ ${ }^{2}$ Banka Slovenije, Slovenska 35, 1505 Ljubljana, Slovenia \\ ${ }^{3}$ School of Economics and Business, Quantitative Economic Analysis, \\ University of Maribor, Razlagova 14, 2000 Maribor, Slovenia

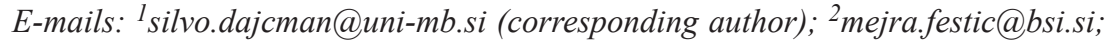 \\ 3alenka.kavkler@uni-mb.si
}

Received 06 June 2011; accepted 14 October 2011

\begin{abstract}
This paper examines the systematic risk and validity of the basic capital asset pricing model of Sharpe (1964), Lintner (1965) and Mossin (1966) in three Central and Eastern European stock markets (i.e. Slovenia, Hungary and Czech Republic). The CAPM is tested on a multiscale basis, building on the Fama and MacBeth (1973) methodology and applying two modern econometric techniques - wavelet analysis and generalized method of moments estimation. Empirical results indicate that the systematic risk and validity of CAPM implications are multiscale phenomena. Empirical evidence in support of CAPM implications in the investigated Central and Eastern European stock markets is found to be weak. The most commonly violated CAPM hypotheses are the zero Jensen's alpha condition, positive market premium, and the non-systematic influence of non-observable variables on the excess returns of stocks in these stock markets.
\end{abstract}

Keywords: stock market, CAPM, Central and Eastern Europe, wavelet analysis, generalized method of moments, systematic risk.

Reference to this paper should be made as follows: Dajčman, S.; Festić, M.; Kavkler, A. 2013. Multiscale test of CAPM for three Central and Eastern European stock markets, Journal of Business Economics and Management 14(1): 54-76.

JEL Classification: G15, G11, D53, D92.

\section{Introduction}

The basic capital asset pricing model (CAPM), developed independently by Sharpe (1964), Lintner (1965) and Mossin (1966), building on the earlier work of Markowitz (1952) on mean-variance portfolio theory, has been the corner-stone of modern finance for the last four decades. Although the CAPM has been extensively empirically studied, the debate about its validity is continuing due to its simplicity, and other alternative asset pricing models not being without theoretical and/or empirical weaknesses, it has been widely applied in financial practice to evaluate not just securities, but any investment. 
Finding evidence in favor or against the validity of CAPM is therefore of great interest for financial public.

CAPM predicts that the risk premium of an individual asset (i.e. excess return of an asset over the risk-free return) should be proportional to the market premium (i.e. excess return of the market portfolio over the risk-free return). The factor of proportionality is known as systematic risk or beta $(\beta)$ of an asset. Since the specific risk of an asset can be diversified away, investors in an asset are compensated only for bearing the systematic risk of an asset. Knowing the beta of an asset and the market premium, one can calculate the expected rate of return for any asset.

The CAPM theory generates four main testable implications: i) The risk premium for any asset with positive beta is positive; ii) There should be a linear relationship between the beta and the excess return of an asset; iii) An asset that is uncorrelated with the market portfolio has an expected return equal to the risk-free rate; and iv) There should be no systematic effect of non-beta risk on the excess returns of an asset. Early empirical studies on CAPM (Douglas 1968; Black 1972; Black et al. 1972; Miller, Scholes 1972; Blume, Friend 1973; Fama, MacBeth 1973) were partially supportive of the implications of the model. They found that the relationship between beta and expected returns is positive; however, the studies consistently found that empirical models underestimated the market premium expected from the theoretical CAPM (Campbell 2000). Many studies in the eighties and nineties questioned the validity of the Sharpe-Lintner-Mossin's CAPM. The empirical studies of Banz (1981), Reinganum (1981), Gibbons (1982), Shanken (1985), and Fama and French (1992) found that the return generation process depended not only on the beta of an asset but also on other variables like size, the book to market ratio and the earnings/price ratio. The further development of the basic CAPM model took two directions. Some authors worked on theoretically extending the basic CAPM model (for instance the zero-beta CAPM of Black (1972), the intertemporal CAPM of Merton (1973), the consumer CAPM of Lucas (1978) and Breeden (1979)) and developing new models of asset pricing (the arbitrage pricing model of Ross (1976) which became the basis for the multifactor asset pricing models). Other authors tried to improve the methods of empirically testing the CAPM.

One strand of empirical studies that try to improve the empirical testing of CAPM, which this paper aims to contribute to, has pointed out the importance of time interval of returns on estimation of beta (Levhari, Levy 1977; Handa et al. 1989, 1993; Brailsford, Faff 1997; Lynch, Zumbach 2003; Gençay et al. 2005; Fernandez 2006; Rhaeim et al. 2007; Aktan et al. 2009). These studies are built on the assumption that economic and financial phenomena may exhibit different characteristics over different time scales as economic agents make decisions about consumption, saving and investing with heterogeneous time horizons. Therefore, not only may systematic risk across time scales differ (Levhari, Levy 1977; Lynch, Zumbach 2003), but also the validity of CAPM may be more relevant for some time scales than for others (Handa et al. 1993; Gençay et al. 2005; Fernandez 2006; Rhaeim et al. 2007; Aktan et al. 2009). To obtain beta estimates for interval returns these studies either apply the data of asset returns for different frequencies, e.g. weekly, monthly or annual returns (Handa et al. 1993; Lynch, 
Zumbach 2003), or apply a wavelet technique to obtain the multiscale estimates of the beta (Gençay et al. 2005; Fernandez 2006; Rhaeim et al. 2007; Aktan et al. 2009). The CAPM is then tested in a two-stage procedure: in the first step the betas of the assets are estimated and in the second the predictions of the CAPM model are tested by either the Fama and MacBeth's (1973) methodology within the ordinary least squares (OLS) regression framework (Gençay et al. 2005; Fernandez 2006; Rhaeim et al. 2007; Aktan et al. 2009; Handa et al. 1993) or by conditional CAPM testing methodology in the GARCH framework (Brailsford, Faff 1997; Lynch, Zumbach 2003).

The aim of the paper is to test the validity of CAPM for three Central and Eastern European stock markets (i.e. for Slovenia, Hungary and the Czech Republic) on a scaleby-scale basis. For this purpose, we propose to test CAPM implications in a modified two-step procedure of Fama and MacBeth (1973).

In the first stage, we follow the studies of Gençay et al. (2005), Fernandez (2006), Rhaeim et al. (2007) and Aktan et al. (2009) to obtain beta estimates for particular shares via a wavelet methodology. Wavelet analysis is a novel technique that enables us to investigate the multiscale features of the systematic risk of the assets. As wavelets are localized in both time and scale, unlike the Fourier analysis and spectral analysis, they thus provide a convenient and efficient way of representing complex variables or signals (Ramsey 1999). The wavelet analysis become extensively used in finance either as a signal decomposition tool (e.g. Mallat, Zhang 1993; Gençay et al. 2001a, 2001b, 2003 ) or a tool to detect interdependence between variables (Gençay et al. 2005; In, Kim 2006; In et al. 2008; Fernandez 2006; Rhaeim et al. 2007).

In the second stage, we test the CAPM implications in the generalized method of moments (GMM) framework. Fama and MacBeth (1973) proposed testing CAPM in the OLS framework. In order to correct for cross-sectional correlation of standard error they ran the second stage equation for portfolio of stocks rather than for individual stocks. The other studies that obtain betas in the first stage by wavelet analysis (Gençay et al. 2005; Fernandez 2006; Rhaeim et al. 2007; Aktan et al. 2009) use the OLS framework in the second stage testing of the CAPM implications by following the Fama and MacBeth suggestion of forming portfolio of stocks. However, this procedure assumes there is no serial correlation in residual returns and suffers from the errors-in-variables problem (MacKinlay, Richardson 1991; Cochrane 2000; Shanken, Zhou 2006), since the betas used in the second stage regression are estimates of the true, unknown betas. The associated tests of CAPM, based on t-statistics, may no longer be valid (Shanken, Zhou 2006). One way to deal with this problem is to use the Shanken's (1992) asymptotic standard errors with a correction factor. The other way, as applied in our study, is to test CAPM using GMM, which yields estimates robust to both the errors-in-variables problem and serial correlation of standard errors.

The paper provides two primary scientific contributions. It examines the validity of CAPM implications for three Central and Eastern European stock markets on a multiscale basis. To our knowledge, there are no other empirical studies providing multiscale evidence on CAPM validity for these stock markets. Next, a contribution to the literature of empirical testing of CAPM is made - a two-stage methodology of testing 
the CAPM implications is proposed, building on the Fama and MacBeth (1973) methodology, and applying two modern econometric techniques (wavelet analysis and the generalized method of moments) which are robust to statistical problems of previous multiscale CAPM tests. Based on the results of the empirical tests on multiscale validity of CAPM, we argue that financial investments, based on CAPM calculation of asset prices, should resort to multiscale estimation of systematic risk, corresponding to investment horizon of the financial investment.

\section{Methodology}

\subsection{The Capital Asset Pricing Model (CAPM)}

The CAPM model of Sharpe (1964), Lintner (1965) and Mossin (1966) emerges from the maximization problem for an economic agent in an environment of uncertainty. Following Blanchard and Fischer (1989) an economic agent with a horizon of $T$ periods wants to maximize his present (discounted) value of expected utility of consumption:

$$
\max E_{0}\left[\sum_{t=0}^{T-1} \frac{1}{(1+\theta)^{t}} U\left(c_{t}\right)\right]
$$

where $E_{0}$ denotes the expectation conditional on information available at time 0 , where $\theta$ is a subjective discount rate, which expresses time preference of the agent. $U\left(c_{t}\right)$ is the utility function, dependent on consumption level $c_{t}$. Let us assume that for a given time $t$ the agent can allocate his wealth among $n-1$ risky assets with a stochastic rate of return $r_{i t}$ and a riskless asset with a rate of return $r_{0 t}$. The maximization results in $n$ first order conditions:

$$
U^{\prime}\left(c_{t}\right)=\frac{E\left[U^{\prime}\left(c_{t+1}\right)\left(1+r_{i t}\right)\right]}{1+\theta}, i=0, \ldots, n-1 .
$$

The economic agent that wants to maximize his total present value consumption utility should choose a consumption path where the marginal utility of the consumption in the present period $t$ equals the discounted expected marginal utility of the consumption for the next period. The first order conditions should hold, regardless of riskiness of the asset (i.e. also for the riskless asset).

By rearranging the first order conditions of (2):

$$
E\left[U^{\prime}\left(c_{t+1}\right)\left(r_{i t}-r_{0 t}\right)\right]=0, i=1, \ldots, n-1,
$$

equation (2) can be rewritten as:

$$
E\left[U^{\prime}\left(c_{t+1}\right)\right] E\left[\left(r_{i t}-r_{0 t}\right)\right]+\operatorname{cov}\left[U^{\prime}\left(c_{t+1}\right), r_{i t}\right]=0, i=1, \ldots, n-1 .
$$

At equilibrium, the rate of return from an asset must satisfy the following equation:

$$
E\left(r_{i t}\right)=r_{0 t}-\frac{\operatorname{cov}\left[U^{\prime}\left(c_{t+1}\right), r_{i t}\right]}{E\left(U^{\prime}\left(c_{t+1}\right)\right]}, i=1, \ldots, n-1 .
$$


According to equation (5), the investor will invest in an asset with an expected rate of return less than the riskless rate of return if the asset return has a positive relationship with the marginal utility of consumption.

Suppose there exists an asset $m$ with a rate of return that is negatively related with the marginal utility of consumption in the next period, so that $U^{\prime}\left(c_{t+1}\right)=-\gamma r_{m t}$ for some positive $\gamma$. It follows that $\operatorname{cov}\left[U^{\prime}\left(c_{t+1}\right), r_{i t}\right]=-\gamma \operatorname{cov}\left(r_{i t}, r_{m t}\right)$. Equation (5) is also valid for the asset $m$ :

$$
E\left(r_{m t}\right)=r_{0 t}-\frac{\operatorname{cov}\left[U^{\prime}\left(c_{t+1}\right), r_{m t}\right]}{E\left(U^{\prime}\left(c_{t+1}\right)\right]}=r_{0 t}+\frac{\gamma \sigma_{m}^{2}}{E\left(U^{\prime}\left(c_{t+1}\right)\right]},
$$

where $\sigma_{m}^{2}$ is the variance of the asset $m$ return.

It follows that:

$$
E\left(r_{i t}\right)=r_{0 t}-\left[\frac{\operatorname{cov}\left(r_{i t}, r_{m t}\right)}{\sigma_{m}^{2}}\right]\left[E\left(r_{m t}\right)-r_{0 t}\right] .
$$

If we assume that $m$ is a market portfolio (consisting of all traded assets in the market), equation (7) represents the security market line in the CAPM. Equation (7) implies that excess returns from asset $i$ (i.e. in excess of the risk-free asset return) should be proportional to the market premium (i.e. market return in excess of the risk-free asset return). The proportionality factor is called the beta $\left(\beta_{i}\right)$ or systematic risk of the asset $i$ :

$$
\beta_{i}=\frac{\operatorname{cov}\left(r_{i t}, r_{m t}\right)}{\sigma_{m}^{2}} .
$$

With a definition of beta, equation (7) can be rewritten as:

$$
E\left(r_{i t}\right)=r_{0 t}+\beta_{i} E\left(r_{m t}-r_{0 t}\right) \text {. }
$$

The term $E\left(r_{m t}-r_{0 t}\right)$ is referred to as the market risk premium, given that it represents the return over the risk-free rate required by investors to hold the market portfolio.

Rearranging equation (9), we obtain:

$$
E\left(r_{i t}\right)-r_{0 t}=\beta_{i} E\left(r_{m t}-r_{0 t}\right),
$$

from which it follows that the risk premium on an individual asset equals its beta time the market risk premium.

In empirical studies $\beta_{i}$ is usually estimated by ordinary least squares (OLS) from the following regression (Fernandez 2006):

$$
\begin{gathered}
r_{i t}-r_{0 t}=\alpha_{i}+\beta_{i}\left(r_{m t}-r_{0 t}\right)+\epsilon_{i t} \text { or alternatively } \\
e r_{i t}=\alpha_{i}+\beta_{i} e r_{m t}+\epsilon_{i t},
\end{gathered}
$$

where $e r_{i t}$ is the excess return of asset $i$ over the riskless asset return in time period $t$, $\alpha_{i}$ is a regression constant, which according to CAPM should be zero for all assets, $e r_{m t}$ is the excess return of market portfolio over riskless asset return in time period $t$ and $\epsilon_{i t}$ is a random error term. 


\subsection{Empirical testing of the CAPM implications}

Following the procedure of Fama and MacBeth (1973), the validity of CAPM can be tested in a two-stage procedure. In the first stage, the time series regressions of equation (11) are run to obtain beta estimates for each stock $i$ for time periods $t$ (time period is usually a year; $t=1, \ldots, T)$. In the second stage, a cross-sectional regression is run:

$$
e r_{i t}=\gamma_{0, t}+\gamma_{1, t} \beta_{i, t}+\gamma_{2, t} \beta_{i, t}^{2}+\gamma_{3, t} R V_{i, t}+\epsilon_{i, t},
$$

over all assets $i(i=1, \ldots, N)$, where $\beta_{i, t}$ are estimates of the betas of the first stage regressions, $R V_{i, t}$ are residual variances of the first stage equation and $\epsilon_{i, t}$ is a random error term.

The CAPM theory generates four main testable implications (Campbell et al. 1997):

1) $H_{0}: \gamma_{0, t}=0\left(\gamma_{0, t}\right.$, called also Jensen's alpha, in Sharpe-Lintner-Mossin's CAPM should be zero);

2) $H_{0}: \gamma_{1, t}>0$ (CAPM implicates that the risk-return trade-off should be positive; stocks with higher beta should generate higher excess returns);

3) $H_{0}: \gamma_{2, t}=0$ (CAPM implicates linear relationship between the beta and the excess return of an asset $i$ );

4) $H_{0}: \gamma_{3, t}=0$ (CAPM implicates no systematic effect of non-beta risk on excess return of an asset $i$ ).

To test the CAPM implications, Fama and MacBeth (1973) suggested using time-series averages as estimates of expected values, and then to test whether these are significantly different from zero with standard t-test. However, this procedure assumes there is no serial correlation in residual returns and suffers from the errors-in-variables problem (MacKinlay, Richardson 1991; Cochrane 2000; Shanken, Zhou 2006), since the betas used in the second stage regression are estimates of the true, unknown betas. The associated tests of CAPM, based on t-statistics, may no longer be valid (Shanken, Zhou 2006). In order to correct for cross-sectional correlation of the standard errors, Fama and MacBeth (1973) suggested to run second stage equations for portfolio of stocks rather than for individual stocks. However, by this procedure the serial correlation in the residual returns and the errors-in-variables problems are still unresolved (MacKinlay, Richardson 1991; Cochrane 2000; Shanken, Zhou 2006). One way to deal with the remaining problems is to use the Shanken's (1992) asymptotic standard errors with a correction factor. The other way is to estimate the second stage equation as a pooled time-series cross-section by generalized method of moments (Cochrane 2000).

\subsection{Empirical testing of CAPM in the Generalized Method of Moments framework}

The Generalized Method of Moments (GMM), originally developed by Hansen (1982), refers to a class of estimators that are constructed by exploiting the sample moment counterparts of population moment conditions (also known as orthogonality conditions) of the data generating model. They became widely used methods in economics and 
finance. Stock market features like volatility clustering ${ }^{1}$, non-normal distribution of returns, or serial correlation make ordinary least squares an inappropriate estimator for the capital asset pricing model. If the returns exhibit heteroscedasticity conditional on the factors or serial correlation, the standard errors of the parameter estimates may not be correct, even asymptotically, and the associated tests may no longer be valid (Shanken, Zhou 2006). As argued by MacKinlay and Richardson (1991), Cochrane (2000), Shanken and Zhou (2006), and Lozano and Rubio (2009), a robust test of the CAPM can be constructed using the GMM because its estimates are robust to both conditional heteroscedasticity and serial correlation in the return residuals. Cochrane (2000) showed that the problem of serially correlated errors and the errors-in-variables can be comprehensively tackled by estimating the CAPM by the GMM. We will use a GMM estimator to test the robustness of the OLS estimates of the validity of the CAPM hypotheses.

The second stage equation of Fama and MacBeth (equation (12)) will be estimated by a two-step GMM estimator.

Let us consider a linear regression model:

$$
y_{t}=z_{t}^{\prime} \delta_{0}+\epsilon_{t}, t=1,2, \ldots, n,
$$

where $z_{t}$ is a $L \times 1$ vector of explanatory variables, $\delta_{0}$ is a vector of unknown coefficients and $\epsilon_{t}$ is a random error term. This model allows for the possibility that some or all of the elements $z_{t}$ may be correlated with the error term $\epsilon_{t}$ (i.e. $E\left[z_{t k} \epsilon_{t}\right] \neq 0$ for some $k$ ). Further, let us assume that there exists a $K \times 1$ vector of instrumental variables $x_{t}$ which may contain some or all of the elements of $z_{t}$. Instrumental variables $x_{t}$ satisfy a set of $K$ orthogonality conditions:

$$
E\left[g_{t}\left(w_{t}, \delta_{0}\right)\right]=E\left[x_{t} \epsilon_{t}\right]=E\left[x_{t}\left(y_{t}-z^{\prime}{ }_{t} \delta_{0}\right)\right]=0,
$$

where $g_{t}\left(w_{t}, \delta_{0}\right)=x_{t} \epsilon_{t}=x_{t}\left(y_{t}-z^{\prime}{ }_{t} \delta_{0}\right)$. The GMM estimator of the parameter vector is given by:

$$
\hat{\delta}(\hat{W})=\left(S_{x z}^{\prime} \hat{W} S_{x z}\right)^{-1} S_{x z}^{\prime} \hat{W} S_{x y},
$$

where $\hat{W}$ is a weight matrix, whereas $S_{x y}=\sum_{t=1}^{n} x_{t} y_{t}$ and $S_{x z}=\sum_{t=1}^{n} x_{t} z_{t}^{\prime}$ are the sample moments. Notation is the same as in Hayashi (2000) and Zivot and Wang (2006).

An efficient two-step GMM estimator utilizes the result that a consistent estimate of $\delta$ may be computed by GMM with an arbitrarily positive definite and symmetric weight matrix $\hat{W}$, such that $\hat{W} \stackrel{p}{\rightarrow} W$ as $n \rightarrow \infty$ ( $W$ is symmetric and positive definite). The most common choices for $\hat{W}$ are $\hat{W}=I_{k}$ ( $I_{k}$ is an identity matrix) or $\hat{W}=S_{x x}^{-1}=\left(n^{-1} X^{\prime} X\right)^{-1}$, where $X$ is dimension $n \times k$ with t-th row equal $x_{t}^{\prime}$. Let us denote $g_{n}(\delta)=\frac{1}{n} \sum_{t=1}^{n} x_{t}\left(y_{t}-z_{t}^{\prime} \delta\right)$. A first step consistent estimate of $S$ (i.e. asymptotic

\footnotetext{
${ }^{1}$ Volatility clustering can be described as departure from the volatility's long-term mean over an extended period of time (Teresiene 2009).
} 
variance-covariance matrix of the sample moment $\left.g_{n}(\delta)\right)$ is obtained by:

$$
\hat{S}(\hat{W})=\frac{1}{n} \sum_{t=1}^{n} x_{t} x_{t}^{\prime}\left(y_{t}-z_{t}^{\prime} \hat{\delta}(\hat{W})\right)^{2} .
$$

The Newey-West estimator with Bartlett kernel weights is used to estimate the GMM asymptotic variance-covariance matrix.

\subsection{Multiscale analysis of systematic risk}

In order to test the CAPM on a multiscale basis, the first stage scale-by-scale estimates of $\beta_{i, t}$ will be obtained by the maximal overlap discrete wavelet transform (MODWT) of first stage regression variables. This procedure will be explained next.

\subsubsection{A basic concept of wavelets}

Similar to Fourier analysis, wavelet analysis involves the projection of the original time series onto a sequence of basis functions, which are known as wavelets. There are two basic wavelet functions: the father wavelet (also known as a scaling function), $\phi$, and the mother wavelet (also known as a wavelet function), $\psi$, which can be scaled and translated to form a basis for the Hilbert space $L^{2}(\mathbb{R})$ of square integrable functions. The father and mother wavelets are defined by the functions:

$$
\begin{aligned}
\phi_{j, k}(t) & =2^{-\frac{j}{2}} \phi\left(2^{-j} t-k\right), \\
\psi_{j, k}(t) & =2^{-\frac{j}{2}} \psi\left(2^{-j} t-k\right),
\end{aligned}
$$

where $j=1, \ldots, J$ is the scaling parameter in a j-level decomposition and $k$ is a translation parameter $(j, k \in \mathbb{Z})$. The long term trend of the time series is captured by the father wavelet, which integrates to 1 , while the mother wavelet, which integrates to 0 , describes fluctuations from the trend. The continuous wavelet transform of a square integrable time series $X(t)$ consists of the scaling, $\alpha_{J, k}$, and wavelet coefficients, $\beta_{j, k}$, (Craigmile, Percival 2002):

$$
\alpha_{J, k}=\int \phi_{J, k}(t) X(t) \text { and } \beta_{j, k}=\int \psi_{j, k}(t) X(t) .
$$

It is possible to reconstruct $X(t)$ from these transform coefficients using:

$$
X(t)=\sum_{k} \alpha_{J, k} \phi_{J, k}(t)+\sum_{k} \beta_{J, k} \psi_{j, k}(t)+\sum_{k} \beta_{J-1, k} \psi_{J-1, k}(t)+\ldots+\sum_{k} \beta_{1, k} \psi_{j, k}(t) \text {. }
$$

\subsubsection{Multiscale beta estimation by the maximal overlap discrete wavelet transform}

In practice, we observe a time series for a finite number of regularly spaced times, so we can make use of a maximal overlap discrete wavelet transform (MODWT). The MODWT is a linear filtering operation that transforms a series into coefficients related to variations over a set of scales. It is similar to the discrete wavelet transform (DWT), but it gives up the orthogonality property of the DWT to gain other features that render MODWT more suitable for the aims of our study. As noted by Percival and Mojfeld 
(1997), this includes: i) the ability to handle any sample size regardless of whether the series is dyadic (that is of size $2^{J_{0}}$ ), or not; ii) increased resolution at coarser scales as the MODWT oversamples the data; iii) translation-invariance, which ensures that MODWT wavelet coefficients do not change if the time series is shifted in a "circular" fashion; and iv) the MODWT produces a more asymptotically efficient wavelet variance estimator than the DWT.

Let $^{2} \boldsymbol{X}$ be an $N$ dimensional vector whose elements represent the real-valued time series $\left\{X_{t}: t=0, \ldots, N-1\right\}$. For any positive integer, $J_{0}$, the level $J_{0}$ MODWT of $\boldsymbol{X}$ is a transform consisting of the $J_{0}+1$ vectors $\widetilde{\boldsymbol{W}}_{1}, \ldots, \widetilde{\boldsymbol{W}_{J_{0}}}$ and $\tilde{\boldsymbol{V}}_{J_{0}}$, all of which have dimension $N$. The vector $\widetilde{\boldsymbol{W}}_{j}$ contains the MODWT wavelet coefficients associated with changes at scale $\tau_{j}=2^{j-1}$ (for $j=1, \ldots, J_{0}$ ), while $\tilde{\boldsymbol{V}}_{J_{0}}$ contains MODWT scaling coefficients associated with averages on scale ${ }^{3} \lambda_{J_{0}}=2^{J_{0}}$. Based upon definition of MODWT coefficients we can write (Percival, Walden 2000):

$$
\widetilde{\boldsymbol{W}_{j}}=\widetilde{\mathcal{W}_{j}} \boldsymbol{X} \text { and } \tilde{\boldsymbol{V}}_{J_{0}}=\tilde{V}_{J_{0}} \boldsymbol{X},
$$

where $\widetilde{\mathcal{W}}_{j}$ and $\tilde{V}_{J_{0}}$ are $N \times N$ matrices. Vectors are denoted by bold.

By definition, the elements of $\tilde{\boldsymbol{W}}_{j}$ and $\tilde{\boldsymbol{V}}_{J_{0}}$ are outputs obtained by filtering $\boldsymbol{X}$, namely:

$$
\tilde{W}_{j, t}=\sum_{l=0}^{L_{j}-1} \tilde{h}_{j, l} X_{t-\operatorname{lmod} N} \text { and } \tilde{V}_{j, t}=\sum_{l=0}^{L_{j}-1} \tilde{g}_{j, l} X_{t-\operatorname{lmod} N},
$$

for $t=0, \ldots, N-1$, where $\tilde{h}_{j, l}$ and $\tilde{g}_{j, l}$ are the jth MODWT wavelet and scaling filters. The MODWT treats the series as if it were periodic, whereby the unobserved samples of the real-valued time series $X_{-1}, X_{-2}, \ldots X_{-N}$ are assigned the observed values at $X_{N-1}, X_{N-2}, \ldots X_{0}$.

The MODWT coefficients are thus given by:

$$
\tilde{W}_{j, t}=\sum_{l=0}^{N-1} \tilde{h}_{j, l}^{\circ} X_{t-\operatorname{lmodN}} \text { and } \tilde{V}_{j, t}=\sum_{l=0}^{N-1} \tilde{g}_{j, l}^{\circ} X_{t-\operatorname{lmodN}},
$$

for $t=0, \ldots, N-1, \tilde{h}_{j, l}^{\circ}$ and $\tilde{g}_{j, l}^{\circ}$ are periodization of $\tilde{h}_{j, l}$ and $\tilde{g}_{j, l}$ to circular filters of length $N$.

This periodic extension of the time series is known as analyzing $\left\{X_{t}\right\}$ using "circular boundary conditions" (Percival, Walden 2000; Cornish et al. 2006). There are $L_{j}-1$ wavelet and scaling coefficients that are influenced by the extension ("the boundary coefficients"). Since $L_{j}$ increases with $j$, the number of boundary coefficients increases

\footnotetext{
${ }^{2}$ Concepts and notations as in Percival and Walden (2000) are used. Another thorough description of MODWT using matrix algebra is found in Gençay et al. (2002).

${ }^{3}$ Percival and Walden (2000) denote scales of MODWT obtained wavelet coefficients with a letter $\tau$ and scales of scaling coefficients with $\lambda$. We use the same notations.
} 
with scale. Exclusion of boundary coefficients in the wavelet variance, wavelet correlation and covariance provides unbiased estimates (Cornish et al. 2006).

Given that market portfolio return time series, $r_{m t}$, and stock $i$ return time series, $r_{i t}$, are stationary processes, a MODWT transformation of the two series can be performed to obtain vectors of wavelet coefficients $\tilde{W}_{j, t}^{\left(r_{m t}\right)}$ and $\tilde{W}_{j, t}^{\left(r_{i t}\right)}$. The estimate of the beta for a stock $i$ at scale $\tau_{j}, \beta_{i}\left(\tau_{j}\right)$, can be obtained by an ordinary least squares regression:

$$
\tilde{W}_{j, t}^{\left(e r_{i t}\right)}=\alpha_{i}\left(\tau_{j}\right)+\beta_{i}\left(\tau_{j}\right) \tilde{W}_{j, t}^{\left(e r_{m t}\right)}+\epsilon_{i t}\left(\tau_{j}\right),
$$

where $\tilde{W}_{j, t}^{\left(e r_{i t}\right)}$ is the scale $\tau_{j}$ vector of wavelet coefficients, not affected by boundary condition, obtained by transforming the time series $e r_{i t}$ by MODWT; $e r_{i t}$ is the excess return of stock $i$ over the return of risk-free asset at time $t ; \tilde{W}_{j, t}^{\left(e r_{m t}\right)}$ is the scale $\tau_{j}$ vector of wavelet coefficients, not affected by the boundary condition, obtained by transforming $e r_{m t}$ by MODWT; $e r_{m t}$ is the excess market return over return of a risk-free asset (i.e. the market premium) at time $t ; \epsilon_{i t}\left(\tau_{j}\right)$ is a white noise error term of the OLS regression at scale $\left(\tau_{j}\right)$, and $\alpha_{i}\left(\tau_{j}\right)$ is a regression constant term at scale $\left(\tau_{j}\right)$.

\section{Empirical results}

\subsection{Data}

Three Central and Eastern European stock markets were considered: the Slovenian, Hungarian and Czech stock markets. The stock markets of Slovenia, the Czech Republic and Hungary are chosen as they share some common characteristics: they are markets with a short post-communist era, relatively small market capitalization ${ }^{4}$; they have a relatively small number of listed companies ${ }^{5}$, and the stock exchanges are owned by a common holding company (together with the Vienna stock exchange, these three CEE stock exchanges form the CEE Stock Exchange Group). These are also the markets with most developed economies (for instance by GDP per capita) in the Central and Eastern Europe. There are also some important differences between them: Czech and Hungarian stocks have attracted many foreign investors (Caporale, Spagnolo 2010), the Slovenian market less so: the stock market turnover and liquidity of shares listed on the Ljubljana stock exchange is smaller than on the Budapest and Prague stock exchanges ${ }^{6}$. An important reason for choosing only these three stock markets was also the availability of

\footnotetext{
${ }^{4}$ The stock market capitalization of all the shares listed on the Ljubljana stock exchange at the end of the year 2010 was, according to FESE (2010), 6.99 billion EUR. The stock market capitalization of all the shares listed on the Prague stock exchange, at the same time, reached 31.92 billion EUR and on the Budapest stock exchange 20.62 billion EUR. To compare this with some developed European stock markets: the stock market capitalization of all the shares listed on the Deutsche Börse at the end of 2010 was 1,066 billion EUR.

${ }^{5}$ At the end of 2010, the Ljubljana stock exchange had 72 different companies listed, the Budapest stock market had 52, and the Prague stock market had 27. According to FESE (2010) NYSE Euronext had 1,135 stock companies listed, the Deutsche Börse 765, and the Vienna stock market 110.

${ }^{6}$ The equity turnover of Ljubljana's stock exchange in 2010 was $€ 0.7$ billion, of the Prague's stock exchange $€ 30.5$ billion and of the Budapest's stock exchange $€ 39.9$ billion (CEEG 2011).
} 
historical data for long enough time period. The data set consisted of stocks quoted in the main stock index of the investigated stock markets (LJSEX for Slovenia, BUX for Hungary and PX for the Czech Republic). These stock indices were taken as proxies for the market portfolio returns. We endeavored to take the longest possible time series of stock (stock index) returns, but at the same time we had to consider the availability of the risk-free asset return time series. A major drawback of testing CAPM in these markets is the low number of quoted stocks and the relatively short historical time series $^{7}$. The daily returns of the 3-month money market rates of the considered countries are taken as proxies for the countries' risk-free returns ${ }^{8}$. Given that we worked with nominal returns, we used a nominal proxy for the risk-free rate.

The first date of observation for the Slovenian stock market was January 1, 2002, for Hungarian stock market it was April 1, 1997 and for the Czech stock market it was January 10, 1995. Stock (and stock indices) returns were calculated as the differences of logarithmic daily closing prices of the stocks or stock indices $\left(\ln \left(P_{t}\right)-\ln \left(P_{t-1}\right)\right.$, where $P$ is a closing price). In cases when there was no trading with a particular stock on a specific day, we took the closing price of the last trading day. We considered stock splits and reverse stock splits and accordingly adjusted prices of the stocks. The data for stock (stock indices) prices were taken from the web pages of Ljubljana, Budapest and Prague stock exchanges.

Tables 1 to 3 present some descriptive statistics of the data. The data appear extremely non-normal. The majority of the return distributions are negatively skewed (especially in the Hungarian and the Czech stock market), possibly due to the large negative returns associated with the financial crises in the observed period ${ }^{9}$. The data also display a high degree of excess kurtosis. Such skewness and kurtosis are common features in asset return distributions, which are repeatedly found to be leptokurtic (Henry 2002). The Jarque-Bera test rejects the hypothesis of normally distributed returns for all stocks as well as stock indices.

The stationarity of stock returns, interest rates, excess returns and market premiums was checked using the Augmented Dickey-Fuller (ADF) test, the Phillips-Perron (PP) and the Kwiatkowski-Phillips-Schmidt-Shin (KPSS) tests. The returns of all the stocks listed on the Budapest and Prague stock exchanges were found to be stationary, whereas the most of the stocks listed on the Ljubljana stock exchange were fractionally integrated

\footnotetext{
${ }^{7}$ Pooling time-series and cross-section data enlarges the dataset, thereby increasing the variability of the data and increasing the efficiency of the GMM estimator.

${ }^{8}$ In empirical literature different proxies are used for risk-free rates. Most often these include: 10-year treasury bills rates (Gençay et al. 2005), 3-month treasury bills (Michailidis et al. 2006), 3-month money market rates (Gençay et al. 2005; Rhaeim et al. 2007) and interest rates paid on bank deposits of diverse maturity (Aktan et al. 2009; Fernandez 2006). We use 3-month money market rates due to the availability of historical data.

9 The Russian financial crisis (in 1998), the dot-com crisis (in 2000), the internet companies stocks bubble burst (in 2002), the Middle East financial crisis (in 2006) and the Global financial crisis (in 2007-2008).
} 
Table 1. Descriptive statistics for returns series of stocks listed at Slovenian stock exchange and its representative national stock index

\begin{tabular}{|c|c|c|c|c|c|c|c|c|c|}
\hline 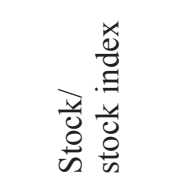 & 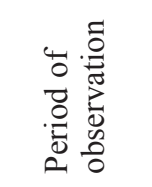 & 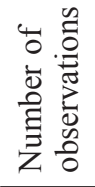 & $\stackrel{\Xi}{\Sigma}$ & 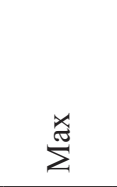 & $\stackrel{\Xi}{\stackrel{\Xi}{\Xi}}$ & 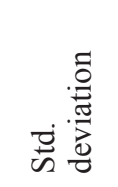 & 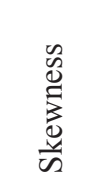 & $\begin{array}{l}\frac{n}{n} \\
\stackrel{0}{U} \\
\stackrel{\Xi}{\Xi}\end{array}$ & 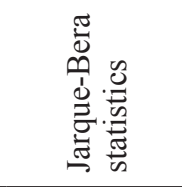 \\
\hline $\begin{array}{l}\text { Aerodrom } \\
\text { Ljubljana }\end{array}$ & $\begin{array}{l}3.1 .2002- \\
20.7 .2010\end{array}$ & 2,132 & -0.1557 & 0.1656 & 0.00022 & 0.02059 & -0.01 & 10.20 & $4,605.59 * * *$ \\
\hline Gorenje & $\begin{array}{l}3.1 .2002- \\
20.7 .2010\end{array}$ & 2.132 & -0.0830 & 0.0831 & 0.00022 & 0.01056 & 0.03 & 6.51 & $1.092 .22 * * *$ \\
\hline Intereuropa & $\begin{array}{l}3.1 .2002- \\
20.7 .2010\end{array}$ & 2,132 & -0.1016 & 0.1542 & -0.00073 & 0.01769 & 0.41 & 12.14 & $7,476.29 * * *$ \\
\hline Krka & $\begin{array}{l}3.1 .2002- \\
20.7 .2010\end{array}$ & 2,132 & -0.1025 & 0.1984 & 0.00079 & 0.01591 & 0.75 & 19.41 & $24,131.11 * * *$ \\
\hline Laško & $\begin{array}{l}3.1 .2002- \\
20.7 .2010\end{array}$ & 2,132 & -0.1504 & 0.1263 & -0.00017 & 0.02110 & -0.16 & 9.01 & $3,215.55 * * *$ \\
\hline Luka Koper & $\begin{array}{l}3.1 .2002- \\
20.7 .2010\end{array}$ & 2,132 & -0.0965 & 0.1281 & 0.00004 & 0.01813 & -0.08 & 7.31 & $1,651.34 * * *$ \\
\hline Mercator & $\begin{array}{l}3.1 .2002- \\
20.7 .2010\end{array}$ & 2,132 & -0.0949 & 0.1129 & 0.00032 & 0.01682 & 0.02 & 8.94 & $3,133.19 * * *$ \\
\hline Petrol & $\begin{array}{l}3.1 .2002- \\
20.7 .2010\end{array}$ & 2,132 & -0.1020 & 0.1328 & 0.000402 & 0.01691 & 0.32 & 12.06 & $7,329.22 * * *$ \\
\hline Sava & $\begin{array}{l}3.1 .2002- \\
20.7 .2010\end{array}$ & 2,132 & -0.1274 & 0.1535 & 0.00040 & 0.01949 & -0.00 & 8.91 & $3,102,66^{* * *}$ \\
\hline $\begin{array}{l}\text { LJSEX } \\
\text { (index) }\end{array}$ & $\begin{array}{l}3.1 .2002- \\
20.7 .2010\end{array}$ & 2,132 & -0.0830 & 0.0831 & 0.00021 & 0.01056 & -0.47 & 15.38 & $13,701.78^{* * *}$ \\
\hline $\begin{array}{l}\text { 3-month } \\
\text { money } \\
\text { market } \\
\text { interest rate }\end{array}$ & $\begin{array}{l}4.1 .2002- \\
20.7 .2010\end{array}$ & 2,132 & 0.0000 & 0.0004 & 0.00018 & 0.00009 & 0.067 & 2.60 & $15.85 * * *$ \\
\hline
\end{tabular}

Notes: Jarque-Bera statistics: *** indicate that the null hypothesis (of normal distribution) is rejected at the $1 \%$ significance level; $* *$ indicate that the null hypothesis is rejected at the $5 \%$ significance level and $*$ indicate that the null hypothesis is rejected at the $10 \%$ significance level.

(i.e. with long range dependence) ${ }^{10}$. Within the GMM framework it is assumed that excess returns and market premiums are stationary and ergodic with finite fourth moments (Hansen 1982; MacKinlay, Richardson 1991). The results (not presented here, but abtainable from the authors) of testing these conditions show that stationarity hypothesis cannot be rejected for the excess returns of stocks and market premiums for the Hungarian and Czech and stock markets, while the excess returns of stocks and a market premium for Slovenian stock market exert long range dependence. The fourth moment (kurtosis) is finite for all the investigated stock returns and market premiums.

${ }^{10}$ These results are not presented here, but can be obtained from the authors. 
Table 2. Descriptive statistics for returns series of stocks listed at Hungarian stock exchange and its representative national stock index

\begin{tabular}{|c|c|c|c|c|c|c|c|c|c|}
\hline 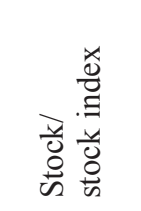 & 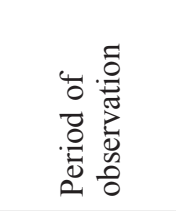 & 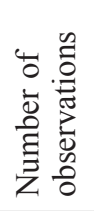 & 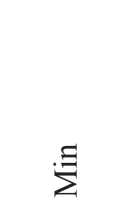 & 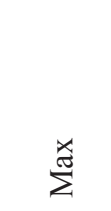 & 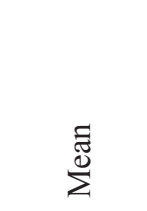 & 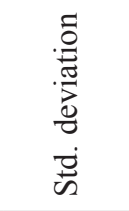 & 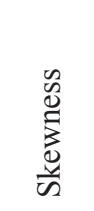 & 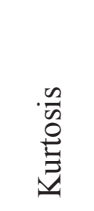 & 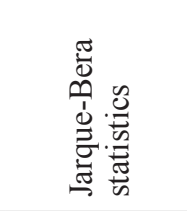 \\
\hline Egis & $\begin{array}{l}1.4 .1997- \\
12.5 .2010\end{array}$ & 3,276 & -0.3567 & 0.1944 & 0.00022 & 0.02676 & -0.97 & 20.41 & $41,904.65^{* * *}$ \\
\hline Fotex & $\begin{array}{l}1.4 .1997- \\
12.5 .2010\end{array}$ & 3,276 & -0.3365 & 0.2346 & 0.00029 & 0.03281 & 0.40 & 13.60 & $15,419.85 * * *$ \\
\hline MOL & $\begin{array}{l}1.4 .1997- \\
12.5 .2010\end{array}$ & 3,276 & -0.2231 & 0.1403 & 0.00058 & 0.02449 & -0.21 & 9.70 & $6,153.19 * * *$ \\
\hline $\begin{array}{l}\text { MTele- } \\
\text { kom }\end{array}$ & $\begin{array}{c}14.11 .1997- \\
12.5 .2010\end{array}$ & 3,119 & -0.1257 & 0.1199 & -0.000031 & 0.02136 & -0.20 & 6.67 & $1,769.98 * * *$ \\
\hline OTP & $\begin{array}{l}1.4 .1997- \\
12.5 .2010\end{array}$ & 3,276 & -0.2513 & 0.2092 & 0.00087 & 0.02782 & -0.22 & 10.80 & $8,321.11 * * *$ \\
\hline Pannergy & $\begin{array}{l}1.4 .1997- \\
12.5 .2010\end{array}$ & 3,276 & -0.2076 & 0.2343 & -0.00019 & 0.02674 & 0.20 & 11.68 & $10,304.38 * * *$ \\
\hline Raba & $\begin{array}{c}17.12 .1997- \\
12.5 .2010\end{array}$ & 3,096 & -0.2501 & 0.1999 & -0.00037 & 0.02600 & -0.14 & 12.56 & $11,794.59 * * *$ \\
\hline Richte & $\begin{array}{l}1.4 .1997- \\
12.5 .2010\end{array}$ & 3,276 & -0.231 & 0.2178 & 0.00040 & 0.02620 & -0.63 & 16.39 & $24,698.68 * * *$ \\
\hline Synergon & $\begin{array}{l}5.5 .1999- \\
12.5 .2010\end{array}$ & 2,759 & -0.1625 & 0.1526 & -0.00056 & 0.02986 & 0.41 & 8.63 & $3,724.70 * * *$ \\
\hline TVK & $\begin{array}{l}1.4 .1997- \\
12.5 .2010\end{array}$ & 3,276 & -0.2231 & 0.2068 & 0.00010 & 0.02755 & -0.15 & 11.84 & $10,683.4 * * *$ \\
\hline $\begin{array}{l}\text { BUX } \\
\text { (index) }\end{array}$ & $\begin{array}{l}1.4 .1997- \\
12.5 .2010\end{array}$ & 3,276 & -0.1803 & 0.1362 & 0.00045 & 0.01924 & -0.64 & 13.18 & $14,367.97 * * *$ \\
\hline $\begin{array}{l}\text { 3-month } \\
\text { money } \\
\text { market } \\
\text { interest } \\
\text { rate }\end{array}$ & $\begin{array}{l}2.4 .1997- \\
12.5 .2010\end{array}$ & 3,276 & 0.0002 & 0.0009 & 0.00043 & 0.00016 & 1.03 & 3.15 & $581.93 * * *$ \\
\hline
\end{tabular}

Note: See notes for Table 1. 
Table 3. Descriptive statistics for returns series of stocks listed at the Czech stock exchange and its representative national stock index

\begin{tabular}{|c|c|c|c|c|c|c|c|c|c|}
\hline 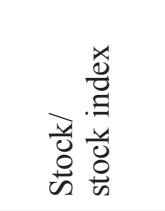 & 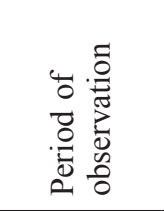 & 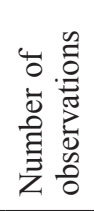 & $\Xi$ & 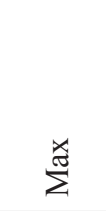 & 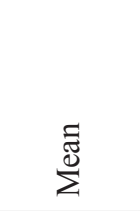 & 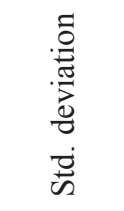 & 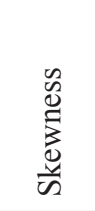 & $\begin{array}{l}\frac{n}{0} \\
\stackrel{0}{0} \\
\stackrel{\Xi}{1}\end{array}$ & 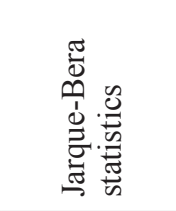 \\
\hline $\begin{array}{l}\text { Auto } \\
\text { Group }\end{array}$ & $\begin{array}{c}26.9 .2007- \\
12.5 .2010\end{array}$ & 654 & -0.1777 & 0.3830 & -0.00182 & 0.03774 & 1.69 & 25.23 & $13,760.99 * * *$ \\
\hline CETV & $\begin{array}{c}26.9 .2007- \\
12.5 .2010\end{array}$ & 655 & -0.237 & 0.3075 & -0.00180 & 0.04803 & 0.28 & 9.01 & $991.58 * * *$ \\
\hline CEZ & $\begin{array}{c}10.1 .1995- \\
12.5 .2010\end{array}$ & 3,596 & -0.1539 & 0.2040 & 0.00062 & 0.02407 & -0.32 & 8.52 & $4,626.25 * * *$ \\
\hline $\begin{array}{l}\text { ECM Real } \\
\text { Estate }\end{array}$ & $\begin{array}{c}1.11 .1997- \\
12.5 .2010\end{array}$ & 629 & -0.2707 & 0.3381 & -0.00282 & 0.04049 & 0.64 & 17.94 & $5,895.57 * * *$ \\
\hline $\begin{array}{l}\text { Erste } \\
\text { Group }\end{array}$ & $\begin{array}{c}26.9 .2007- \\
12.5 .2010\end{array}$ & 654 & -0.1836 & 0.1632 & -0.00088 & 0.03751 & -0.11 & 7.37 & $521,34 * * *$ \\
\hline $\begin{array}{l}\text { Komerčni } \\
\text { Banka }\end{array}$ & $\begin{array}{c}10.1 .1995- \\
12.5 .2010\end{array}$ & 3,596 & -0.2076 & 0.1594 & 0.00024 & 0.02684 & -0.31 & 7.62 & $3,263.82 * * *$ \\
\hline ORCO & $\begin{array}{c}26.9 .2007- \\
12.5 .2010\end{array}$ & 654 & -0.3185 & 0.2646 & -0.00427 & 0.05067 & -0.06 & 9.55 & $1,169.40 * * *$ \\
\hline $\begin{array}{l}\text { Philip } \\
\text { Moris }\end{array}$ & $\begin{array}{c}10.1 .1995- \\
12.5 .2010\end{array}$ & 3,596 & -0.1634 & 0.1263 & 0.00020 & 0.02435 & -0.31 & 6.94 & $2,386.91 * * *$ \\
\hline Telefonica & $\begin{array}{c}28.3 .1995- \\
12.5 .2010\end{array}$ & 3,596 & -0.1281 & 0.1299 & 0.00012 & 0.02184 & -0.02 & 6.93 & $2,316.04 * * *$ \\
\hline Unipetrol & $\begin{array}{c}26.8 .1997- \\
12.5 .2010\end{array}$ & 3,187 & -0.1704 & 0.1799 & 0.00015 & 0.0263 & -0.13 & 7.61 & $2,829.18 * * *$ \\
\hline PX (index) & $\begin{array}{c}10.1 .1995- \\
12.5 .2010 \\
\end{array}$ & 3,596 & -0.1619 & 0.1236 & 0.00028 & 0.01492 & -0.41 & 14.88 & $21,256.18 * * *$ \\
\hline $\begin{array}{l}\text { 3-month } \\
\text { money } \\
\text { market } \\
\text { interest } \\
\text { rate }\end{array}$ & $\begin{array}{c}10.1 .1995- \\
12.5 .2010\end{array}$ & 3,597 & 0.0001 & 0.0014 & 0.00023 & 0.00019 & 1.75 & 6.64 & $3,823.02 * * *$ \\
\hline
\end{tabular}

Note: See notes for Table 1.

\subsection{Results of testing CAPM implications}

In order to test the CAPM implications in a proposed two-step procedure, we in the first-stage estimated systematic risk (i.e. beta) of stocks in the stock markets on a scaleby-scale basis. The beta for each individual stock was re-calculated for each subsample of 250 trading days (approximately one trading year) over the full observation period. For Slovenia's stock market, the effective observation period, for which the CAPM was tested, was therefore January 3, 2002 - January 8, 2010 and was the same for all stocks. There were in total 72 observations in the second stage regression to test CAPM implications for the Slovenian stock market. For the Hungarian stock market, 
the effective observation period for the calculation of the betas stretched from April 5, 2000 - April 2, 2010, and was the same for all observed stocks. The total number of observations in the second stage equation amounted to 100 observations. For the Czech stock market, the effective period of observation was from January 9, 1996 - December 21, 2009; however due to a data availability issue it was different for individual stocks. The total number of observations in the second stage equation of testing implications of CAPM was $78^{11}$.

The MODWT transformation of excess returns of the stocks and market premiums was performed using a Daubechies least asymmetric filter with a wavelet filter length of 8 (LA8). This is a common wavelet filter in other empirical studies on financial markets (Gençay et al. 2005; Fernandez 2006; Rhaeim et al. 2007; Ranta 2010). Since the daily data of excess returns and market premiums were used in our analysis, the maximum level of decomposition we used was $J_{0}=6,(j=1, \ldots, 6)$. The wavelet scale $\tau_{1}$ measures the dynamics of returns over $2-4$ days, scale $\tau_{2}$ over 4-8 days, scale $\tau_{3}$ over 8-16 days, scale $\tau_{4}$ over 16-32 days, scale $\tau_{5}$ over $32-64$ days and scale $\tau_{6}$ over $64-128$ days. To obtain the unbiased estimates of the betas, the MODWT boundary condition was handled by using a "reflection boundary condition" (Percival, Walden 2000). We found that betas of stocks vary from scale to scale, confirming the findings in literature that systematic risk is a multiscale phenomenon. The results are not presented here as they are only an input in the second stage regression of testing CAPM implications.

In the second stage of testing the CAPM implications, we applied the GMM framework. For the purpose of comparison, we also performed an OLS regression and reported these results as well. To assert that the CAPM is valid for a stock market, the null hypotheses must not be rejected.

Hypotheses are tested based on two-sided t-test, except for the hypothesis $H_{0}: \gamma_{1, t}>0$ where one-sided t-test is used. We tested the CAPM for raw returns (in this CAPM model, the betas in the first step were obtained on raw, MODWT non-transformed, returns), and for return dynamics of wavelet scales $\tau_{1}$ to $\tau_{6}$. We also report the average daily market premium in the period for which the CAPM was tested.

The results of the OLS regression show that the explanatory power (as measured by $\mathrm{R}^{2}$ ) of the CAPM for the raw (i.e. daily) returns is weak, but increases higher wavelet scales (see Tables 4 through 6). We notice that for Slovenian stock market the greatest explanatory power of CAPM is achieved for wavelet scale $\tau_{6}$ and for Hungarian stock market for wavelet scale $\tau_{1}$. For the Czech stock market, the average of $\mathrm{R}^{2}$ across all CAPM models is higher than for the Slovenian and Hungarian stock market, meaning the CAPM has greater explanatory power for the excess returns of stocks in the Czech stock market. CAPM in the Czech stock market best explains scale $\tau_{6}$ (corresponding to investment horizon over 32-64 days) excess return dynamics.

\footnotetext{
${ }^{11}$ For the Czech stock market we have an unbalanced panel. This is because for the Czech stock market a relatively long time series of return series is available only for 5 different stocks (see Table 3). To have large enough number of observations to test the CAPM implications, we estimated an unbalanced panel of pooled time-series cross-section data.
} 
Table 4. OLS and GMM results of testing the CAPM implications for the Slovenian stock market

\begin{tabular}{|c|c|c|c|c|c|}
\hline & $\gamma_{0}$ & $\gamma_{1}$ & $\gamma_{2}$ & $\gamma_{3}$ & $\begin{array}{l}\text { Statistical parameters } \\
\text { of OLS regression }\end{array}$ \\
\hline $\begin{array}{l}\text { The raw } \\
\text { returns } \\
\text { model }\end{array}$ & $\begin{array}{c}0.0017226 \\
(1.5842) \\
(4.0906) * * *\end{array}$ & $\begin{array}{c}-0.0028493 \\
(-0.9188) \\
(-1.1368)\end{array}$ & $\begin{array}{c}0.0010036 \\
(0.4667) \\
(0.4574)\end{array}$ & $\begin{array}{c}-0.0003844 \\
(-0.1748) \\
(-1.9077)\end{array}$ & $\begin{array}{l}\mathrm{R}^{2}=0.0474 \\
\mathrm{DW}=2.3611\end{array}$ \\
\hline Scale $\tau_{1}$ & $\begin{array}{c}0.0030379 \\
(3.2739)^{* * *} \\
(3.9668)^{* * *}\end{array}$ & $\begin{array}{c}-0.0046549 \\
(-1.7047) \\
(-1.6664)\end{array}$ & $\begin{array}{c}0.0023998 \\
(1.2449) \\
(1.0606) \\
\end{array}$ & $\begin{array}{c}-7.710092 \\
(-3.964) * * * \\
(-3.8933) * * *\end{array}$ & $\begin{array}{c}\mathrm{R}^{2}=0.2532 \\
\mathrm{DW}=2.4535\end{array}$ \\
\hline Scale $\tau_{2}$ & $\begin{array}{c}0.0026197 \\
(2.7954)^{* * *} \\
(6.6680)^{* * *}\end{array}$ & $\begin{array}{c}-0.0037492 \\
(-1.6487) \\
(-3.1191) \\
\end{array}$ & $\begin{array}{c}0.001870 \\
(1.3045) \\
(1.7976) \\
\end{array}$ & $\begin{array}{c}-17.2757427 \\
(-2.8209)^{* * *} \\
(-3.5271)^{* * *}\end{array}$ & $\begin{array}{c}\mathrm{R}^{2}=0.1487 \\
\mathrm{DW}=2.5909\end{array}$ \\
\hline Scale $\tau_{3}$ & $\begin{array}{c}0.0026623 \\
(2.4106)^{* *} \\
(5.3394)^{* * *}\end{array}$ & $\begin{array}{c}-0.0026533 \\
(-1.0619) \\
(-1.3943)\end{array}$ & $\begin{array}{c}0.0010027 \\
(0.6635) \\
(0.7065) \\
\end{array}$ & $\begin{array}{l}-51.4099179 \\
(-3.7277) * * * \\
(-4.4703) * * *\end{array}$ & $\begin{array}{c}\mathrm{R}^{2}=0.1886 \\
\mathrm{DW}=2.5633\end{array}$ \\
\hline Scale $\tau_{4}$ & $\begin{array}{c}0.0016307 \\
(2.3055)^{* *} \\
(5.1414)^{* * *}\end{array}$ & $\begin{array}{c}-0.000967 \\
(-0.645) \\
(-1.0791) \\
\end{array}$ & $\begin{array}{c}0.00000635 \\
(0.0069) \\
(0.007900)\end{array}$ & $\begin{array}{c}-71.6956619 \\
(-2.0858)^{* *} \\
(-2.5624)^{* *}\end{array}$ & $\begin{aligned} \mathrm{R}^{2} & =0.102 \\
\mathrm{DW} & =2.5641\end{aligned}$ \\
\hline Scale $\tau_{5}$ & $\begin{array}{c}0.0010343 \\
(1.8088)^{*} \\
(2.4308)^{* *}\end{array}$ & $\begin{array}{c}-0.0008610 \\
(-1.5395) \\
(-4.5264)\end{array}$ & $\begin{array}{c}0.0000468 \\
(0.1216) \\
(0.1996) \\
\end{array}$ & $\begin{array}{c}-45.1373426 \\
(-0.7427) \\
(-0.7714) \\
\end{array}$ & $\begin{array}{c}\mathrm{R}^{2}=0.0494 \\
\mathrm{DW}=2.4818\end{array}$ \\
\hline Scale $\tau_{6}$ & $\begin{array}{c}0.0008870 \\
(1.7634)^{*} \\
(3.1269)^{* * *} \\
\end{array}$ & $\begin{array}{c}-0.0007791 \\
(-1.1321) \\
(-2.4630)\end{array}$ & $\begin{array}{c}-0.00008766 \\
(-0.2117) \\
(-0.2266) \\
\end{array}$ & $\begin{array}{c}23.9927004 \\
(0.2183) \\
(0.1955) \\
\end{array}$ & $\begin{array}{c}\mathrm{R}^{2}=0.6791 \\
\mathrm{DW}=1.0401\end{array}$ \\
\hline
\end{tabular}

Average daily market premium in the effective period of testing the CAPM $=0.00003333$

Notes: The raw returns model presents the results of testing the CAPM implications where betas in the first stage of the procedure are calculated on raw returns data (i.e. wavelet untransformed data or daily returns). As the GMM is just identified, the OLS and GMM estimates of gammas are equal. In the first parenthesis the t-statistics based on the OLS estimates of the gammas are presented and in the second parentheses under the gamma estimates t-statistics based on GMM estimates of the gammas are presented. Exceeded critical values for the rejection of the null hypotheses are indicated by *** for a $1 \%$ significance level, by $* *$ for a $5 \%$ significance level and by * for a $10 \%$ significance level.

One can see that the t-statistics of the regression coefficients estimated by OLS and GMM differ. The Durbin-Watson statistics point out the problem of serial correlation. As we previously noted, the problems of estimating pooled time-series cross-section version of the CAPM by OLS are due to heteroscedasticity and the serial correlation in returns, which in turn makes the standard errors of the parameter estimates incorrect, even asymptotically. The associated tests based on t-statistics may no longer be valid; therefore inferences regarding the CAPM hypotheses should be made on the basis of the robust results of the GMM estimator.

Regarding the CAPM hypotheses, the following conclusions may be drawn from the GMM estimator results:

- The hypothesis of zero Jensen's alpha, $H_{0}: \gamma_{0, t}=0$, that must not be rejected if CAPM is valid, is generally rejected for the Slovenian stock market. For the Hungar- 
Table 5. OLS and GMM results of testing the CAPM implications for Hungarian stock market

\begin{tabular}{|c|c|c|c|c|c|}
\hline & $\gamma_{0}$ & $\gamma_{1}$ & $\gamma_{2}$ & $\gamma_{3}$ & $\begin{array}{l}\text { Statistical parameters } \\
\text { of OLS regression }\end{array}$ \\
\hline $\begin{array}{l}\text { The raw } \\
\text { returns } \\
\text { model }\end{array}$ & $\begin{array}{c}0.0016614 \\
(1.9750)^{*} \\
(2.9183)^{* * *} \\
\end{array}$ & $\begin{array}{c}-0.0022957 \\
(-1.0615) \\
(-1.3952)\end{array}$ & $\begin{array}{c}0.0010059 \\
(0.7140) \\
(0.8684)\end{array}$ & $\begin{array}{c}-2.327127 \\
(-3.4344)^{* * *} \\
(-2.3450) * *\end{array}$ & $\begin{array}{l}\mathrm{R}^{2}=0.1199 \\
\mathrm{DW}=2.348\end{array}$ \\
\hline Scale $\tau_{1}$ & $\begin{array}{c}0.0016817 \\
(2.2575)^{* *} \\
(3.1465)^{* * *}\end{array}$ & $\begin{array}{c}-0.0020719 \\
(-1.0641) \\
(-1.3956)\end{array}$ & $\begin{array}{c}0.0009235 \\
(0.6953) \\
(0.8023)\end{array}$ & $\begin{array}{c}-5.2062058 \\
(-3.8781)^{* * *} \\
(-2.67822)^{* * *}\end{array}$ & $\begin{aligned} \mathrm{R}^{2} & =0.147 \\
\mathrm{DW} & =2.3111\end{aligned}$ \\
\hline Scale $\tau_{2}$ & $\begin{array}{r}0.0015469 \\
(1.9495)^{*} \\
(2.4867)^{* *} \\
\end{array}$ & $\begin{array}{c}-0.0023548 \\
(-1.2522) \\
(-1.6735)\end{array}$ & $\begin{array}{c}0.0012020 \\
(1.0117) \\
(1.3053)\end{array}$ & $\begin{array}{c}-8.9222896 \\
(-3.3656)^{* * *} \\
(-1.9197)^{*}\end{array}$ & $\begin{array}{l}\mathrm{R}^{2}=0.1127 \\
\mathrm{DW}=2.296\end{array}$ \\
\hline Scale $\tau_{3}$ & $\begin{array}{c}0.0013178 \\
(1.9414)^{*} \\
(1.7363)\end{array}$ & $\begin{array}{c}-0.0020981 \\
(-1.1923) \\
(-0.9028)\end{array}$ & $\begin{array}{c}0.0010014 \\
(0.8834) \\
(0.6931)\end{array}$ & $\begin{array}{l}-16.6414480 \\
(-3.2448)^{* * *} \\
(-2.9870)^{* * *}\end{array}$ & $\begin{array}{c}\mathrm{R}^{2}=0.1129 \\
\mathrm{DW}=2.4454\end{array}$ \\
\hline Scale $\tau_{4}$ & $\begin{array}{c}0.0008520 \\
(1.1968) \\
(1.6319)\end{array}$ & $\begin{array}{c}-0.0001620 \\
(-0.0994) \\
(-0.1389)\end{array}$ & $\begin{array}{c}-0.0005302 \\
(-0.5522) \\
(-0.7645)\end{array}$ & $\begin{array}{c}-29.5496919 \\
(-2.8795)^{* * *} \\
(-2.5956)^{* * *}\end{array}$ & $\begin{array}{c}\mathrm{R}^{2}=0.1051 \\
\mathrm{DW}=2.4703\end{array}$ \\
\hline Scale $\tau_{5}$ & $\begin{array}{c}0.0004296 \\
(1.0204) \\
(1.1809) \\
\end{array}$ & $\begin{array}{c}-0.0006927 \\
(-1.0849) \\
(-1.0809)\end{array}$ & $\begin{array}{c}0.0002313 \\
(0.5365) \\
(0.4650) \\
\end{array}$ & $\begin{array}{c}-35.5379933 \\
(-2.2386)^{* *} \\
(-2.4041)^{* *}\end{array}$ & $\begin{array}{c}\mathrm{R}^{2}=0.0603 \\
\mathrm{DW}=2.5344\end{array}$ \\
\hline Scale $\tau_{6}$ & $\begin{array}{c}0.0004375 \\
(1.0455) \\
(1.3744)\end{array}$ & $\begin{array}{c}-0.0007058 \\
(-0.9819) \\
(-1.3072)\end{array}$ & $\begin{array}{c}0.0002957 \\
(0.8646) \\
(1.1958)\end{array}$ & $\begin{array}{c}-106.8265938 \\
(-3.5265)^{* * *} \\
(-3.3503)^{* * *}\end{array}$ & $\begin{array}{c}\mathrm{R}^{2}=0.1185 \\
\mathrm{DW}=2.3455\end{array}$ \\
\hline
\end{tabular}

Average daily market premium in the effective period of testing rhe CAPM $=0.00003313$

Notes: See notes for Table 4.

ian stock market; however, the hypothesis is not rejected for wavelet scales $\tau_{3}$ to $\tau_{6}$ and for the Czech stock market for the raw returns and wavelet scales $\tau_{3}, \tau_{4}$ and $\tau_{6}$.

- According to CAPM one should expect a positive relationship between risk (as measured by beta) and return, meaning that the stocks with higher beta should generate higher excess returns. This in turn means that the security market line has a positive slope ${ }^{12}$. For the CAPM to be valid in investigated stock markets, the hypothesis $H_{0}: \gamma_{1, t}>0$ must not be rejected ${ }^{13}$. The hypothesis can be rejected for all stock markets.

\footnotetext{
${ }^{12}$ In fact, if all of the observed stocks well represent the market portfolio, then on the basis of the CAPM theory we should expect an average daily excess return to equal the average daily historical market premium (i.e. excess return of the market portfolio over the risk-free rate). The later was positive for all stock markets: an average daily market premium in the effective observation period was $0.00333 \%$ for the Slovenian stock market, $0.003313 \%$ for the Hungarian stock market and $0.002519 \%$ for the Czech stock market. As the average (weighted) beta of all the stocks representing market portfolio is per definition 1 , then $\gamma_{1, t}$ should equal the historical market premium. Therefore, we should expect $\gamma_{1, t}$ to be positive and close to the historical market premium.

${ }^{13}$ The empirical null hypothesis is $H_{0}^{\prime}: \gamma_{1}=0$ and the alternative hypothesis $H_{0}^{\prime}: \gamma_{1}>0$, what is the opposite from the null hypothesis $H_{0}: \gamma_{1, t}>0$ written above.
} 
Table 6. OLS and GMM results of testing the CAPM implications for the Czech stock market

\begin{tabular}{|c|c|c|c|c|c|}
\hline & $\gamma_{0}$ & $\gamma_{1}$ & $\gamma_{2}$ & $\gamma_{3}$ & $\begin{array}{c}\text { Statistical parameters } \\
\text { of OLS regression }\end{array}$ \\
\hline $\begin{array}{l}\text { The raw } \\
\text { returns } \\
\text { model }\end{array}$ & $\begin{array}{c}0.0013403 \\
(1.3969) \\
(1.7263)\end{array}$ & $\begin{array}{c}-0.0016320 \\
(-0.8152) \\
(-0.7263)\end{array}$ & $\begin{array}{c}0.0008760 \\
(0.8098) \\
(0.5976)\end{array}$ & $\begin{array}{l}-1.9239822 \\
(-3.8927)^{* * *} \\
(-3.3691)^{* * *}\end{array}$ & $\begin{array}{c}\mathrm{R}^{2}=0.1701 \\
\mathrm{DW}=2.6387\end{array}$ \\
\hline Scale $\tau_{1}$ & $\begin{array}{c}0.0012513 \\
(1.6069) \\
(2.0825)^{* *}\end{array}$ & $\begin{array}{c}-0.0011470 \\
(-0.8043) \\
(-0.8583)\end{array}$ & $\begin{array}{c}0.00060268 \\
(0.6978) \\
(0.6054)\end{array}$ & $\begin{array}{l}-3.8715827 \\
(-3.4946) * * * \\
(-3.2663)^{* * *}\end{array}$ & $\begin{array}{c}\mathrm{R}^{2}=0.1464 \\
\mathrm{DW}=2.6498\end{array}$ \\
\hline Scale $\tau_{2}$ & $\begin{array}{c}0.0014114 \\
(1.5786) \\
(2.8825) * * *\end{array}$ & $\begin{array}{c}-0.0022774 \\
(-1.1663) \\
(-1.3740)\end{array}$ & $\begin{array}{c}0.0011587 \\
(1.0789) \\
(1.0217)\end{array}$ & $\begin{array}{l}-6.3959734 \\
(-3.4339)^{* * *} \\
(-2.9857)^{* * *}\end{array}$ & $\begin{array}{c}\mathrm{R}^{2}=0.1481 \\
\mathrm{DW}=2.5717\end{array}$ \\
\hline Scale $\tau_{3}$ & $\begin{array}{c}0.0011302 \\
(1.3047) \\
(1.7626)^{*}\end{array}$ & $\begin{array}{c}-0.0016343 \\
(-0.9592) \\
(-1.07580)\end{array}$ & $\begin{array}{c}0.0006552 \\
(0.8323) \\
(0.7906)\end{array}$ & $\begin{array}{l}-10.8993042 \\
(-3.4776)^{* * *} \\
(-2.3686)^{* * *}\end{array}$ & $\begin{array}{c}\mathrm{R}^{2}=0.1535 \\
\mathrm{DW}=2.5225\end{array}$ \\
\hline Scale $\tau_{4}$ & $\begin{array}{c}0.0005087 \\
(0.6005) \\
(0.9999)\end{array}$ & $\begin{array}{c}-0.00000362 \\
(-0.0023) \\
(-0.0026)\end{array}$ & $\begin{array}{c}0.0000216 \\
(0.031795) \\
(0.0274)\end{array}$ & $\begin{array}{c}-32.9996030 \\
(-4.3256) * * * \\
(-4.138774) * * *\end{array}$ & $\begin{array}{c}\mathrm{R}^{2}=0.2022 \\
\mathrm{DW}=2.5291\end{array}$ \\
\hline Scale $\tau_{5}$ & $\begin{array}{c}0.0007546 \\
(1.2384) \\
(2.213851)^{* *}\end{array}$ & $\begin{array}{c}-0.0017561 \\
(-1.6084) \\
(-2.6671)\end{array}$ & $\begin{array}{c}0.0011311 \\
(2.3295)^{* *} \\
(3.4117)^{* * *}\end{array}$ & $\begin{array}{l}-68.219816 \\
(-4.7254)^{* * *} \\
(-4.3507)^{* * *}\end{array}$ & $\begin{array}{c}\mathrm{R}^{2}=0.2576 \\
\mathrm{DW}=2.5072\end{array}$ \\
\hline Scale $\tau_{6}$ & $\begin{array}{c}0.0002361 \\
(0.5086) \\
(0.8393)\end{array}$ & $\begin{array}{c}-0.0011234 \\
(-1.6993) \\
(-2.6049)\end{array}$ & $\begin{array}{c}0.0007235 \\
(2.2280)^{* *} \\
(3.3360)^{* * *}\end{array}$ & $\begin{array}{r}-100.5335394 \\
(-3.2369)^{* * *} \\
(-2.171988)^{* *}\end{array}$ & $\begin{array}{c}\mathrm{R}^{2}=0.1331 \\
\mathrm{DW}=2.4782\end{array}$ \\
\hline
\end{tabular}

Average daily market premium in the effective period of testing the CAPM $=0.00002519$

Notes: See notes for Table 4.

- The hypothesis of a linear relationship between the betas of the stocks and their excess returns $\left(H_{0}: \gamma_{2, t}=0\right)$ cannot be rejected for any of the CAPM models for the Slovenian and Hungarian stock market. For the Czech stock market, the non-linear relationship between the betas and excess returns could be identified for wavelet scales $\tau_{5}$ and $\tau_{6}$.

- The results of the second stage regression of testing the CAPM implications show that there are significant other factors, beside the beta of the stocks that can significantly explain excess returns of stocks in the three CEE stock markets. These are especially important for the Hungarian and Czech stock market as $\gamma_{3, t}$ is significantly different from zero for all investment horizons (scales), which is inconsistent with the CAPM theory. In the Slovenian stock market, the systematic effect of non-beta factors on the excess returns on stocks is found for wavelet scales $\tau_{1}$ to $\tau_{4}$.

Based on these results, we may conclude that support for the CAPM implications in the investigated CEE stock markets is weak. For the Slovenian stock market, the raw returns model seems to best support the CAPM hypotheses, however the intercept is significantly different from zero, and the market premium is not significantly positive which is inconsistent with the CAPM. There are at least two violations of the CAPM implications at each wavelet scale. For Hungarian stock market, the evidence against 
the CAPM is the strongest for the raw returns and wavelet scales $\tau_{1}$ and $\tau_{2}$. The CAPM implications seem to be more relevant for investors with longer investment horizons (of at least 8-16 days). However, the rejection of the hypothesis of positive market premium and significant relevance of unobservable factors, not captured by the beta, weakens the validity of the CAPM in the Hungarian stock market. For the Czech stock market, the results indicate that the beta does not fully explain all variability in the excess returns of the stocks in the market. The weakest evidence against CAPM is found in the shortest and medium term investment horizons (i.e. for the raw returns and scales $\tau_{3}$ and $\tau_{4}$ ), which suggest that CAPM may be more relevant for these investment horizons which is an important implication for financial public in the investigated CEE countries. Financial investments based on CAPM calculation of asset prices should resort to multiscale estimation of systematic risk, corresponding to investment horizon of the financial investment.

The CAPM hypotheses that seem to be most often violated are the zero Jensen's alpha condition, a positive market premium and non-systematic influence of non-observable variables on excess returns of stocks in the market. The Jensen's alpha (intercept) in the estimated CAPM models is found to be positive. As shown by Jarrow and Protter (2011), a non-zero alpha implies an arbitrage opportunity, which is a stronger violation of market efficiency. For Slovenian stock market, the estimated intercepts are significantly different from zero (by t-test) for all CAPM models, whereas for the Hungarian and the Czech stock market the intercepts are not significantly different from zero for higher wavelet scales (scales $\tau_{3}$ to $\tau_{6}$; exception being CAPM model of wavelet scale $\tau_{3}$ for the Czech stock market). Further, according to CAPM, the systematic risk is the only factor that determines the excess returns of stocks in an efficient stock market. However, the significant parameter estimates $\gamma_{3, t}$ show that the beta (i.e. systematic or market risk) cannot fully explain the variability in excess returns in the markets. There are other, by model non-observable variables, that influence excess returns of stocks in all the investigated markets, regardless of time scale. Violations of these two CAPM hypotheses indicate that the efficiency of the investigated stock markets is questionable ${ }^{14}$.

Our results support the findings of other studies that systematic risk and CAPM are multiscale phenomena (Gençay et al. 2005; Fernandez 2006; Rhaeim et al. 2007; Bortoluzzo et al. 2010). However these studies use different methodology and test only predictions regarding Jensen's alpha and positive market premium. Gençay et al. (2005) found that for the United States stock market, the implications of CAPM are more relevant for investors with medium to long-term (wavelet scales $\tau_{2}$ and $\tau_{3}$ ) horizons as compared to those with short-term horizons as estimates of $\gamma_{1, t}$ for these scales best approximated the historical market premium. For the German stock market, the CAPM predictions are the most relevant for wavelet scale $\tau_{3}$, corresponding to 8-16 days investment horizon dynamics. Mid and higher wavelet scales were also found to better capture risk-return relationship in the United Kingdom's stock market. Fernandez (2006), who analyzed

${ }^{14}$ There are some studies of stock market efficiency of CEE countries (Gilmore, McManus 2002; Worthington, Higgs 2004; Kasman et al. 2009), mainly rejecting their efficiency. 
the stock market in Chile, observed that CAPM is the most relevant for wavelet scale $\tau_{2}$, because the estimated market risk premium for this scale is the closest to the actual risk premium ( $\gamma_{1, t}$ in her study, however, was not significantly larger than zero). Rhaeim et al. (2007) studied the French stock market and concluded that the predictions of the CAPM are more relevant in the short term than in the long term, which makes the French market different from those of the United States, Germany, and the United Kingdom. Aktan et al. (2009) found that for the Turkish stock market, CAPM is most relevant for wavelet scale $\tau_{3}$. Bortoluzzo et al. (2010) showed that based on the t-test and $\mathrm{R}^{2}$, the CAPM performed the best for wavelet scales $\tau_{1}$ to $\tau_{3}$.

\section{Conclusion}

In this paper the systematic risk and validity of four testable implications of CAPM for three Central and Eastern European stock markets (namely in Slovenia, Hungary and the Czech Republic) was investigated on a multiscale basis. A modification of the Fama and MacBeth (1973) methodology was proposed, where in the first stage the systematic risk of individual stocks in the stock markets was calculated applying a wavelet methodology. In the second stage regression, four CAPM implications were tested in the generalized method of moments framework. We found that the systematic risk and validity of the CAPM implications is a multiscale phenomenon. Empirical evidence in support of the CAPM implications in the investigated CEE stock markets was found to be weak. The CAPM hypotheses that seem to be the most commonly violated in these stock markets are the zero Jensen's alpha condition, a positive market premium and non-systematic influence of non-observable variables on the excess returns of stocks in these stock markets.

The results of our study indicate that CAPM implications in the Slovenian stock market may be more relevant for investors with daily rather than longer-term investment horizons. For the Hungarian stock market, the CAPM may be more relevant for investors with investment horizons of at least 8-16 days while for the Czech stock market, CAPM is of the most relevance for investors with investment horizons of 8-32 days.

\section{References}

Aktan, B.; Mabrouk, B. A.; Ozturk, M.; Rhaeim, N. 2009. Wavelet-based systematic risk estimation, an application on Istanbul stock exchange, International Research Journal of Finance and Economics 23(3): 33-45.

Banz, W. R. 1981. The relation between return and market value of common stocks, Journal of Financial Economics 9(1): 3-18. http://dx.doi.org/10.1016/0304-405X(81)90018-0

Black, F. 1972. Capital market equilibrium with restricted borrowing, Journal of Business 45(3): 444-454. http://dx.doi.org/10.1086/295472

Black, F.; Jensen, M. C.; Scholes, M. 1972. The capital asset pricing model: some empirical tests, in M. C. Jensen (Ed.). Studies in the Theory of Capital Markets. New York: Praeger, 79-121.

Blanchard, O.; Fischer, S. 1989. Lectures on Macroeconomics. Cambridge: MIT Press.

Blume, M.; Friend, I. 1973. A new look at the capital asset pricing model, Journal of Finance 28(1): 19-33. http://dx.doi.org/10.1111/j.1540-6261.1973.tb01342.x 
Bortoluzzo, A. B.; Minardi A.; Passos, B. 2010. Analysis of multiscale systemic risk in Brazil's, Insper Working Paper WPE 226/2010. Instituto de Ensino e Pesquisa.

Brailsford, J. T.; Faff, R. W. 1997. Testing the conditional CAPM and the effect of intervaling: a note, Pacific Basin Finance Journal 5(5): 353-372.

http://dx.doi.org/10.1016/S0927-538X(97)00018-8

Breeden, T. D. 1979. An intertemporal asset pricing model with stochastic consumption and investment opportunities, Journal of Financial Economics 7(3): 265-296.

http://dx.doi.org/10.1016/0304-405X(79)90016-3

Campbell, J. Y. 2000. Asset pricing at the Millennium, Journal of Finance 55(4): 1515-1567. http://dx.doi.org/10.1111/0022-1082.00260

Campbell, J. Y; Lo, A. W.; MacKinlay, A. C. 1997. The Econometrics of Financial Markets. Princeton, N.J.: Princeton University Press.

Caporale, M. G.; Spagnolo N. 2010. Stock market integration between three CEEC's, Brunel University Working Paper No. 10-9. Brunel University, West London.

CEEG. 2011. Fact Sheet January 2011 [online], [cited 10 April 2011]. Available from Internet: http://www.ceeseg.com

Cochrane, H. J. 2000. Asset Pricing. New Jersey: Princeton University Press.

Cornish, R. C.; Bretherton, C. S.; Percival, D. B. 2006. Maximal overlap discrete wavelet statistical analysis with application to atmospheric turbulence, Boundary-Layer Meteorology 119(2): 339-374. http://dx.doi.org/10.1007/s10546-005-9011-y

Craigmile, F. P.; Percival, D. B. 2002. Wavelet-based trend detection and estimation, in A. El-Shaarawi, W. W. Piegorsch (Eds.). Entry in the Encyclopedia of Environmetrics. Chichester: John Wiley \& Sons, 2045-2049.

Douglas, G. W. 1968. Risk in the Equity Markets: An Empirical Appraisal of Market Efficiency. Ann Arbor, Michigan: University Microfilms, Inc.

Fama, F. E.; French, K. R. 1992. The cross-section of expected stock returns, Journal of Finance 47(2): 427-465. http://dx.doi.org/10.1111/j.1540-6261.1992.tb04398.x

Fama, F. E.; MacBeth, J. D. 1973. Risk, return, and equilibrium: empirical tests, Journal of Political Economy 81(3): 607-636. http://dx.doi.org/10.1086/260061

Fernandez, V. 2006. The CAPM and value at risk at different time-scales, International Review of Financial Analysis 15(3): 203-219. http://dx.doi.org/10.1016/j.irfa.2005.02.004

FESE - Federation of European Securities Exchanges. 2010. European Securities Exchange Statistics [online], [cited 4 April 2011]. Available from Internet: http://www.fese.be.

Gençay, R.; Selcuk, F.; Whitcher, B. 2001a. Scaling properties of foreign exchange volatility, Physica A: Statistical Mechanics and its Applications 289(1-2): 249-266.

Gençay, R.; Selçuk, F.; Whitcher, B. 2001b. Differentiating intraday seasonalities through wavelet multi-scaling, Physica A 289: 543-556. http://dx.doi.org/10.1016/S0378-4371(00)00463-5

Gençay, R.; Selçuk, F.; Whitcher, B. 2002. An Introduction to Wavelet and Other Filtering Methods in Finance and Economics. San Diego: Academic Press.

Gençay, R.; Selcuk, F.; Whitcher, B. 2003. Systematic risk and timescales, Quantitative Finance 3(2): 108-116. http://dx.doi.org/10.1088/1469-7688/3/2/305

Gençay, R.; Whitcher, B.; Selçuk, F. 2005. Multiscale systematic risk, Journal of International Money and Finance 24(1): 55-70. http://dx.doi.org/10.1016/j.jimonfin.2004.10.003

Gibbons, M. R. 1982. Multivariate test of financial models: a new approach, Journal of Financial Economics 10(1): 3-27. http://dx.doi.org/10.1016/0304-405X(82)90028-9

Gilmore, G. C.; McManus, G. M. 2002. International portfolio diversification: US and Central European equity markets, Emerging Markets Review 3(1): 69-83.

http://dx.doi.org/10.1016/S1566-0141(01)00031-0 
Handa, P.; Kothari, S. P; Wasley, C. 1989. The relation between the return interval and Betas: implications for the size effect, Journal of Financial Economics 23(1): 79-100. http://dx.doi.org/10.1016/0304-405X(89)90006-8

Handa, P.; Kothari, S. P.; Wasley, C. 1993. Sensitivity of multivariate tests of the capital asset pricing to the return interval measurement, Journal of Finance 48(4): 15-43.

http://dx.doi.org/10.1111/j.1540-6261.1993.tb04767.x

Hansen, L. P. 1982. Large sample properties of generalized method of moments estimations, Econometrica 50(4): 1029-1054. http://dx.doi.org/10.2307/1912775

Hayashi, F. 2000. Econometrics. New Jersey: Princeton University Press.

Henry, O. T. 2002. Long memory in stock returns: some international evidence, Applied Financial Economics 12(10): 725-729. http://dx.doi.org/10.1080/09603100010025733

In, F.; Kim, S. 2006. The hedge ratio and the empirical relationship between the stock and futures markets: a new approach using wavelet analysis, Journal of Business 79(2): 799-820.

http://dx.doi.org/10.1086/499138

In, F.; Kim, S.; Marisetty, V.; Faff, R. W. 2008. Analyzing the performance of managed funds using the wavelet multiscaling method, Review of Quantitative Finance and Accounting 31(1): 55-70. http://dx.doi.org/10.1007/s11156-007-0061-8

Jarrow, R.; Protter, P. 2011. Positive alphas, abnormal performance and illusory arbitrage, Mathematical Finance [published online]. http://dx.doi.org/10.1111/j.1467-9965.2011.00489.x

Kasman, S.; Turgutlu, E.; Ayhan, D. A. 2009. Long memory in stock returns: evidence from the major emerging central european stock markets, Applied Economics Letters 16(17): 1763-1768. http://dx.doi.org/10.1080/13504850701663231

Levhari, D.; Levy, H. 1977. The capital asset pricing model and the investment horizon, Review of Economics and Statistics 59(2): 92-104. http://dx.doi.org/10.2307/1924908

Lintner, J. 1965. The valuation of risky assets and the selection of risky investments in stock portfolios and capital budgets, Review of Economics and Statistics 47(1): 13-37.

http://dx.doi.org/10.2307/1924119

Lozano, M.; Rubio, G. 2009. Evaluating alternative methods for testing asset pricing models with historical data, Documento de trabajo [working paper] WP-CEU-UCH EE 2009-01. Universidad Cardenal Herrera.

Lucas, E. R. 1978. Asset prices in an exchange economy, Econometrica 46(6): 1429-1445. http://dx.doi.org/10.2307/1913837

Lynch, P. E.; Zumbach, G. O. 2003. Market heterogeneities and the causal structure of volatility, Quantitative Finance 3(4): 320-331. http://dx.doi.org/10.1088/1469-7688/3/4/308

MacKinlay, A. C.; Richardson, M. P. 1991. Using generalized method of moments to test meanvariance efficiency, The Journal of Finance 46(2): 511-527.

http://dx.doi.org/10.1111/j.1540-6261.1991.tb02672.x

Markowitz, H. 1952. Portfolio selection, Journal of Finance 7(1): 77-91.

Merton, C. R. 1973. An intertemporal capital asset pricing model, Econometrica 41(5): 867-887. http://dx.doi.org/10.2307/1913811

Michailidis, G.; Tsopoglu, S.; Papanastasiou, M. E. 2006. Testing the capital asset pricing model (CAPM): the case of the emerging Greek securities market, International Research Journal of Finance and Economics 4: 78-91.

Miller, M.; Scholes, M. 1972. Rate of return in relation to risk: a reexamination of some recent findings, in M. C. Jensen (Ed.). Studies in the Theory of Capital Markets. New York: Praeger, 47-78.

Mossin, J. 1966. Equilibrium in a capital asset market, Econometrica 34: 768-783. http://dx.doi.org/10.2307/1910098 
Percival, D. B.; Mojfeld, H. O. 1997. Analysis of subtidal coastal sea level fluctuations using wavelets, Journal of the American Statistical Association 92(439): 868-880.

http://dx.doi.org/10.1080/01621459.1997.10474042

Percival, D. B.; Walden, A. T. 2000. Wavelet Methods for Time Series Analysis. New York: Cambridge University Press.

Ramsey, B. J. 1999. The contribution of wavelets to the analysis of economic and financial data, in B. W. Silverman, C. J. Vassilicos (Eds.). Wavelets the Key to Intermittent Information? New York: Oxford University Press, 221-236.

Ranta, M. 2010. Wavelet multiresolution analysis of financial time series, Acta Wasaensia Papers No. 223. Universitas Wasaeensis.

Reinganum, M. R. 1981. Misspecification of capital asset pricing, Journal of Financial Economics 9(1): 19-46. http://dx.doi.org/10.1016/0304-405X(81)90019-2

Rhaeim, N.; Ammou, B. S.; Mabrouk, B. A. 2007. Wavelet estimation of systematic risk at different time scales, application to French stock market, The International Journal of Applied Economics and Finance 1(2): 113-119. http://dx.doi.org/10.3923/ijaef.2007.113.119

Ross, A. S. 1976. The arbitrage theory of capital asset pricing, Journal of Economic Theory 13(3): 341-360. http://dx.doi.org/10.1016/0022-0531(76)90046-6

Shanken, J. 1985. Multivariate tests of the Zero-Beta CAPM, Journal of Financial Economics 14(3): 327-348. http://dx.doi.org/10.1016/0304-405X(85)90002-9

Shanken, J. 1992. On the estimation of Beta-Pricing models, Review of Financial Studies 5(1): 1-34. http://dx.doi.org/10.1093/rfs/5.1.1

Shanken, J.; Zhou, G. 2006. Estimating and testing Beta Pricing models: alternative methods and their performance in simulations, NBER Working Paper 12055. Cambridge: National Bureau of Economic Research.

Sharpe, F. W. 1964. Capital asset prices: a theory of market equilibrium under conditions of risk, Journal of Finance 19(3): 425-442.

Teresiene, D. 2009. Lithuanian stock market analysis using a set of Garch models, Journal of Business Economics and Management 10(4): 349-360.

http://dx.doi.org/10.3846/1611-1699.2009.10.349-360

Worthington, C. A.; Higgs, H. 2004. Random walks and market efficiency in European equity markets, Global Journal of Finance and Economics 1(1): 59-78.

Zivot, E.; Wang, J. 2006. Modeling Financial Time Series with S-PLUS. $2^{\text {nd }}$ ed. New York: Springer.

Silvo DAJČMAN, PhD, a Teaching Assistant of Finance and Banking, School of Economics and Business, University of Maribor. His areas of interest are financial markets, banking and monetary policy.

Mejra FESTIĆ, PhD, is Associate Professor of Economic Theory and Policy, Banking and Finance employed at the University of Maribor. She has been a Vice-rector for the field of academic affairs at the University of Maribor and the principal of the institute EIPF Economic Institute, established in 1963, specialized for economic dynamics forecasts in world economies, Euro area and Europe. Her research field regards to financial stability, monetary systems, banking, finance, capital structure, bank risks management and coordination of economic policies. From the first March 2011 she is employed as a vice-governor at the Bank of Slovenia.

Alenka KAVKLER, PhD, is Assistant Professor for Quantitative Economic Analysis at the Faculty for Economics and Business, University of Maribor, Slovenia. She finished her PhD in the field of Mathematical Methods in Economics at the Vienna University of Technology. Her research interests involve smooth transition regression models, duration models, matching methods and tree models. 